\title{
A brief review on lavatory cleaning devices and their feasibility in public toilets in developing countries
}

\author{
R. Hari Krishnan ${ }^{1}[\mathbb{D}$
}

Received: 7 March 2020 / Accepted: 27 June 2020 / Published online: 8 July 2020

(c) Springer Nature Singapore Pte Ltd. 2020

\begin{abstract}
The purpose of this article is twofold, one is to provide a brief review on various lavatory cleaning devices while the other is to study the feasibility of using these devices in public toilets in developing countries. The article presents a literature review on various lavatory cleaning devices, focusing on various designs available as patent documents and commercially available toilet cleaning robots. The issues that prevent these devices from being deployed in multi-lavatory public toilet complexes in developing countries are discussed. Design considerations of a simple, cost-effective, semi-automated lavatory cleaning robot that may serve as a solution to these issues are also covered in this article.
\end{abstract}

Keywords Service robotics $\cdot$ Automation $\cdot$ Toilet cleaning $\cdot$ Public toilets $\cdot$ Sanitation

\section{Introduction}

The need for sanitation of public toilets is a common and important issue. Public bathrooms carry a large number of bacteria, fungi and viruses. These germs can spread from the toilet seat to body parts of the user and also to other surfaces to which the person is in contact with, spreading infectious diseases to other people (Gerhardts et al. 2012; Ahmed 2018). Human excreta is a main source of transmission of many classical diseases including urinary, anal and vaginal infections (Greed 2006) and studies have shown that toilet seats are always contaminated with faecal bacteria (Mendes and Lynch 1976). Faecal borne bacteria such as Escherichia coli (E. coli), Shigella sonnei, Streptococcus, Staphylococcus, Salmonella, Yersinia and viruses such as norovirus, rotavirus, adenovirus, Torque teno virus spread from toilet surfaces (Gerhardts et al. 2012; Greed 2006; Mendes and Lynch 1976; Sassi et al. 2018) and can result in several serious health issues. Flushing of toilets or cleaning lavatories using pressurized water jet streams can also result in aerosolization of the above mentioned bacteria and viruses which can cause transmission of infectious diseases such as Severe Acute Respiratory Syndrome (SARS) (Gerhardts et al. 2012;

R. Hari Krishnan

harikrishnan.r@mech.sastra.edu

1 School of Mechanical Engineering, SASTRA Deemed to be University, Thanjavur 613 401, Tamil Nadu, India
Greed 2006; Mendes and Lynch 1976; Johnson et al. 2013; Hamilton et al. 2018).

One of the promising approaches to reduce the spreading of toilet bound infectious diseases is to use anti-microbially active surfaces in public toilets (Gerhardts et al. 2012; Greenhalgh and Walker 2017; Querido et al. 2019). Still, the basic requirement is to perform scheduled periodic cleaning of public bathrooms (Querido et al. 2019; ASEAN 2016). In toilets in public places such as schools, universities, hospitals, bus stands, train stations and airports where there are several lavatories to be kept clean and hygienic, the only available cleaning equipment is generally limited to a toilet cleaning brush. Studies show that, among the toilets in public places, hospital toilets are considered to be less hygienic as it would be used by several persons who are suffering from various diseases including gastrointestinal disorders or staphylococcal infections (Greed 2006; Mendes and Lynch 1976). More importantly, effective cleaning of lavatories in public toilets is even more critical for developing countries, where people affected by toilet bound infectious diseases may not have economic resources or awareness to receive appropriate medication (Maiti et al. 2015; Grover and Citro 2011; WHO 2017).

Further, cleaning a lavatory is considered an unpleasant chore and cleaning several such lavatories with just a brush involves a lot of time and effort. Even though several designs of lavatory cleaning systems have been proposed as patents, only a very few devices have been developed 
and commercialized. This paper provides a brief review on lavatory cleaning devices, focussing on various designs available as patent documents and commercially available toilet cleaning robots. Most of these devices serve the purpose of either cleaning only the toilet seat or only the inner wall of the toilet bowl. An efficient lavatory cleaning device shall effectively clean both the seat and the inner wall. Also, most of these expensive devices are meant to be fixed permanently on to the toilet commode, serving that commode alone making the system unaffordable to be employed in a multi-lavatory public toilet complex. Taking into account of these limitations and many more, preliminary design considerations that may lead to the development of a semi-automated lavatory cleaning robot have been discussed towards the end of this paper. The paper is organized in such a way that Sect. 2 covers literature review and Sect. 3 discusses major challenges and issues to be overcome in the existing systems, to be used in public toilets. Design considerations of a semi-automated lavatory cleaning device are discussed in Sect. 4 followed by concluding remarks in Sect. 5 .

\section{Literature review}

\subsection{Lavatory cleaning equipments in patent literature}

Several designs of toilet cleaning brushes were proposed by various inventors. In which, designs proposed by Mayberry (1982), Miller (1983), Dolah (2001) and Moss (2005) stand apart as these brushes are electrically powered-motor operated or have some sort of mechanisms to dispense cleansing agents. Yehuda et al. had put forward a design of a combination toilet cleaning device that can be used as a plunger for grasping and removal of items that may clog the toilet outlet and also as a toilet cleaning brush (Yehuda and Lebenhartz 2016).

In 1997, a design of a toilet cleaning device with a cleaning pad was proposed by Federico et al. (1997). The device made of plastic, has a handle with a trigger on one side and a pair of grasper jaws on the other side. Where, one jaw is fixed (upper) and the other jaw (lower) is hinged to move towards (close) or away (open) from/to the fixed jaw when the trigger is manipulated. A cleaning pad made of biodegradable paper is also part of the design. The pad has a double-wall, double envelope design with a centre layer called 'tongue'. The walls of the pad contain dry detergents. The user grasps the handle of the device and presses the trigger moving the lower jaw slightly downwards to open the jaw. Now the grasper jaws can be inserted into the cleaning pad and subsequently the trigger can be released. This allows the grasper jaws to be clamped down on to the tongue of the cleaning pad. The pad can now be moistened and the lavatory can be cleaned by scrubbing the pad on its surface. As shown in Fig. 1, the device has a 15 degree bend between the handle and its tip which will allow the cleaning pad to reach the interior surface of the bowel. Even though, most of the inner corners of the lavatory can be cleaned with this device, the cleaning process may involve similar time and effort as that of a manual toilet brush.

Another toilet cleaning system was proposed by $\mathrm{Yu}$ in 1998, which can automatically clean the toilet seat before or after toilet usage (Yu 1998). The system, as shown in Fig. 2, consists of a horizontally rotatable toilet seat placed on top of a toilet bowl along with a motor and a transmission mechanism to turn the toilet seat horizontally. A brush attached to another motor is used to clean the toilet seat while it is being turned and a water outlet tube is employed to sprinkle water to the brush for cleaning purpose. A waste water tank is also included to hold the water falling from the movable seat after cleaning. Provisions are also provided in the design to include an electric dryer to dry the wet toilet seat after cleaning. To initiate the cleaning process the control circuit is activated through a switch or an infrared sensor. Once activated, the toilet seat is moved horizontally backward towards a slot between the flush tank and the toilet commode employing associated mechanisms. Underneath the toilet seat, there is a pair of racks on either side of the vertical walls of the same. These racks are engaged with a gear attached to a motor and hence, when the motor is rotated, the toilet seat is also rotated horizontally. Subsequently, the control circuit will energize the second motor which will rotate the brush over the top surface of the toilet seat. Water will be sprinkled on the brush and a provision of a chemical dispenser is also provided to dispense antiseptics or perfumes to this water outlet. The waste water after the cleaning is collected in a waste water tank positioned right under the cleaning brush. Then an electrical dryer is turned

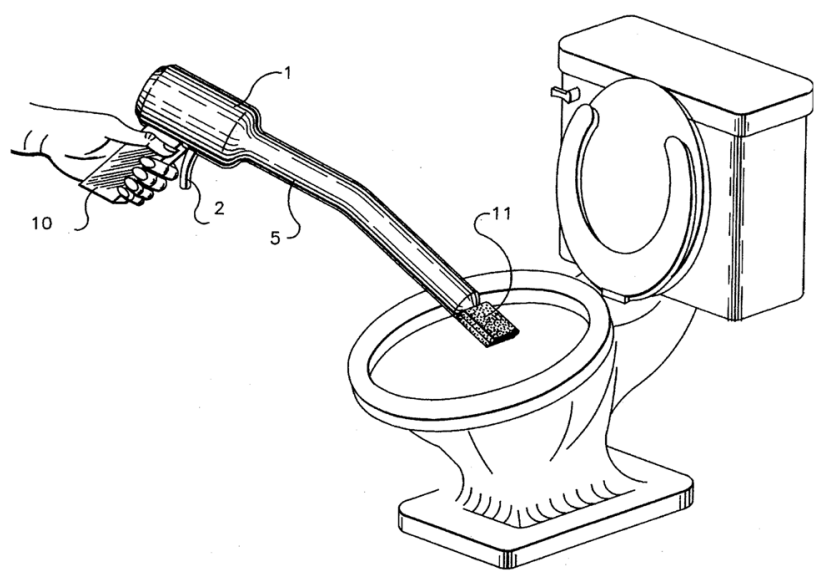

Fig. 1 An illustration of using the device proposed by Federico et al. to clean a toilet commode (Federico and Gabella 1997) 


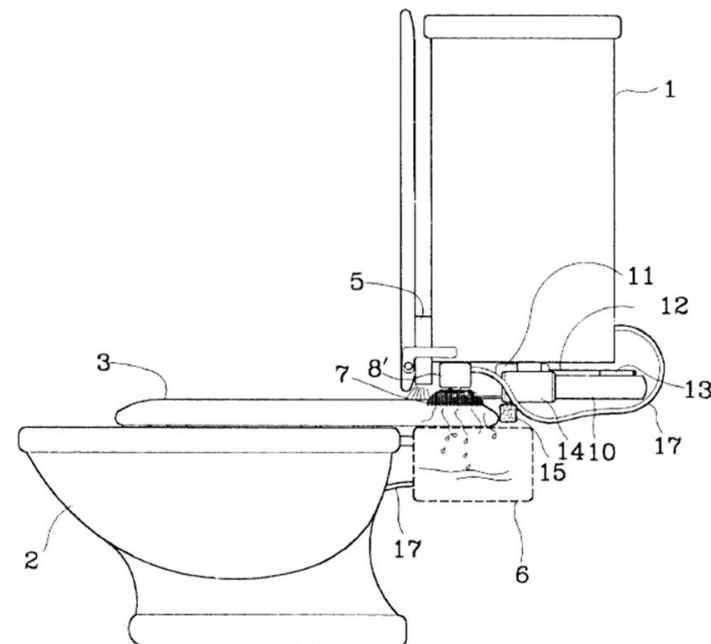

(a)

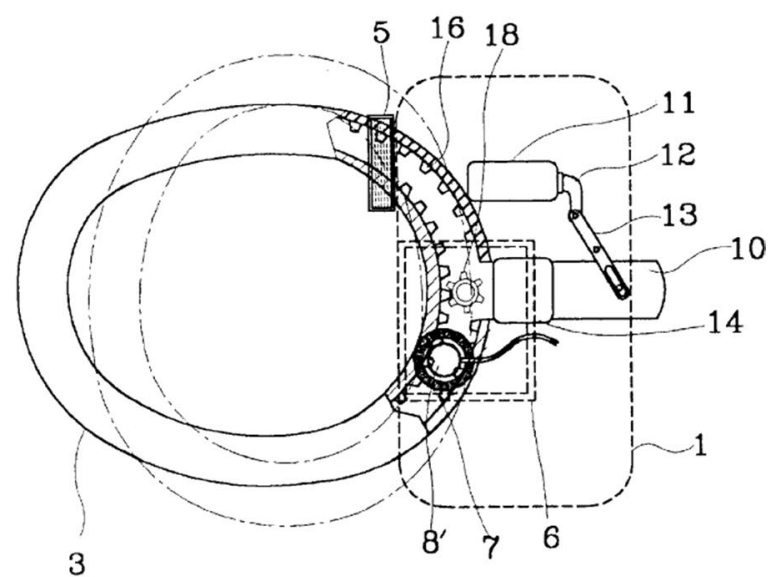

(b)

Fig. 2 Design of toilet cleaning system as proposed by Yu a side view; b top view; (Yu 1998)

on to dry the wet toilet seat. When the toilet seat completes one complete rotation, the control circuit ceases its operation stopping all the cleaning and associated processes and then enters to a stand-by mode. Even though, the system thoroughly cleans the toilet seat, existence of mechanisms to turn the toilet seat horizontally make the design complicated. Moreover, major modification is required in the existing toilet bowl to install this system or toilet commodes should be available commercially with this cleaning system pre-fixed on to it thereby increasing the cost factor in both the cases. Such a system is not affordable to be used in public toilets in developing countries, as each toilet commode in a toilet complex should be installed with one such cleaning system.

Figure 3a shows another apparatus, meant for automatic washing, sanitizing and drying toilet seat, proposed by Sadegh et al. (1999). The device consists of a pivotally connected toilet seat cover with three independent tubes to carry water and hot air. It also consists of a toilet seat, a water collector means and a control unit. From Fig. 3b, c, it can be observed that there are two water tubes with small holes located on the interior and exterior rims of the toilet seat cover to allow the water to reach and wash all areas of the toilet seat completely. The third tube which carries the hot air is located on the middle rim and has larger holes to ensure that the seat is dried properly. The water after cleaning the seat will be collected in the water collector means located at the outer edge of the seat and the collected water will be drained into the toilet bowel through tubes provided as illustrated in Fig. 3c. Provisions are available in the design to avoid splashing of water out of the toilet seat onto the floor while cleaning. The opening and closing of the toilet seat may be automated by employing a motor controlled by the control unit. The entire cleaning process is also controlled by the control unit wherein, the cleaning process starts either by pressing a button or by triggering a photosensor/proximity switch provided when the seat cover is closed.

The device is less complicated when compared to the device proposed by Yu, as it do not have any moving mechanisms to achieve cleaning. One of the major limitation of the design is that, the inner part of the rim cannot be cleaned forming a dead zone. As mentioned for the previous system, several such devices need to be installed to implement this cleaning scheme in a multi-lavatory public toilet complex. A similar device was proposed by Pellati (2004). The inventor claims that the design is structurally and constructively simple as the method followed to feed the disinfectant fluid and hot air has been simplified, when compared to the previous designs. This results in improved efficiency and ease of assembly \& maintenance of the device. The device is also capable of cleaning the dead zones of the toilet seat ring as well. A design of a minimal energy-consuming device for cleaning toilet seat was proposed by Blatz et al. (2004). The device includes associated mechanisms and a mobile cleaning unit which can be moved along the upper surface of the toilet seat making use of water power.

Ermini (2006) had come up with a design of self-sanitizing toilet seat, which is illustrated in Fig. 4. It consists of a ring-shaped seat, placed over a toilet bowl, on which the user will be sitting. In the rear part of the seat, close to the wall, adjacent to/below the conventional water flush tank, there is a box-like structure bearing a plurality of nozzles. The casing above the box-like structure includes electronic circuits for controlling the functioning of these nozzles based on the status of the sensor provided in the same to detect the presence of the user. When the sensor triggers the circuit, the water $\&$ gas circuits which are housed inside the casing 


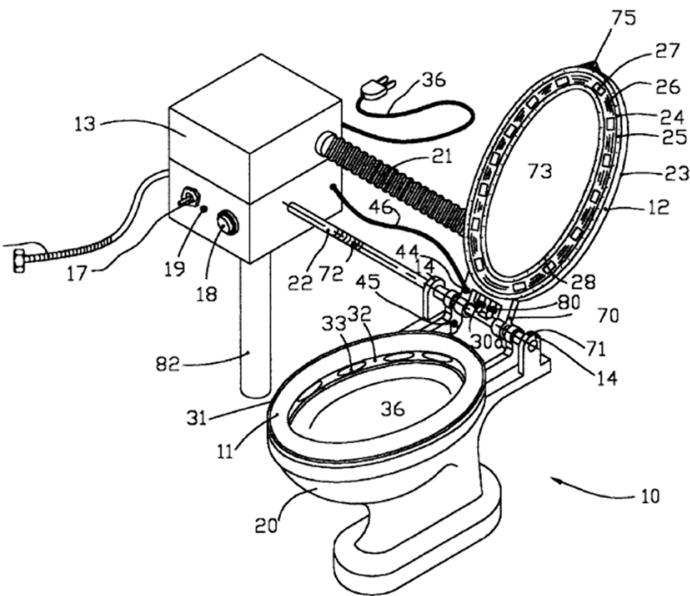

(a)

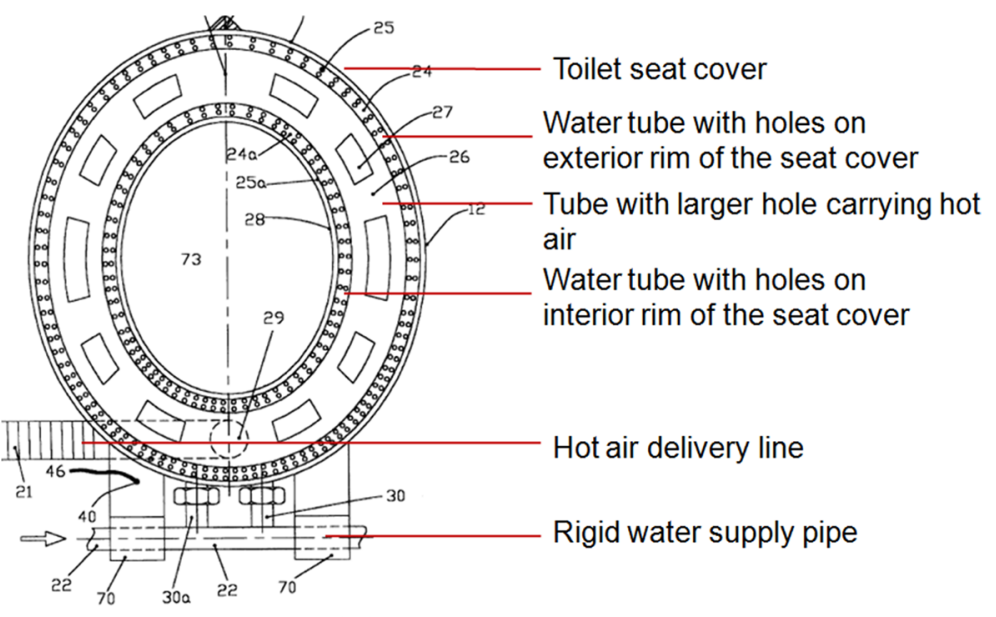

(b)

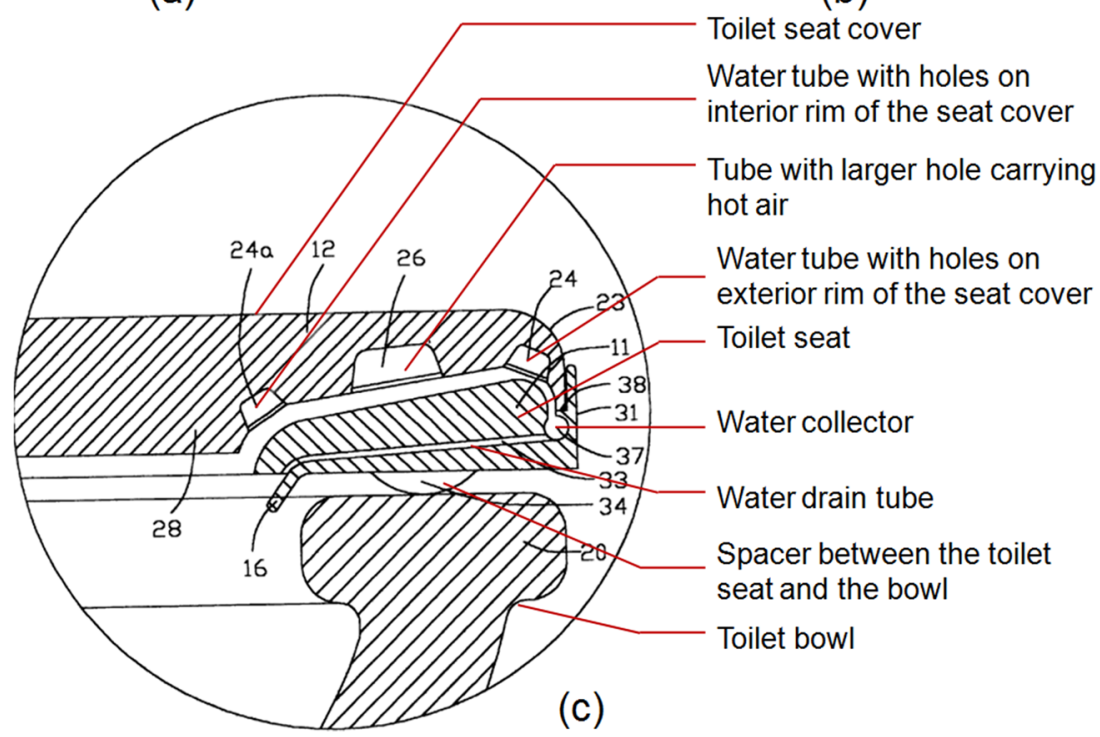

Fig. 3 a Design of automatic toilet cleaning apparatus invented by Sadegh et al.; b bottom view of the toilet seat cover; $\mathbf{c}$ Enlarged section of the outer edge of the toilet seat in closed position (Sadegh et al. 1999)

Fig. 4 Design of self-sanitizing toilet seat proposed by Ermini (2006)

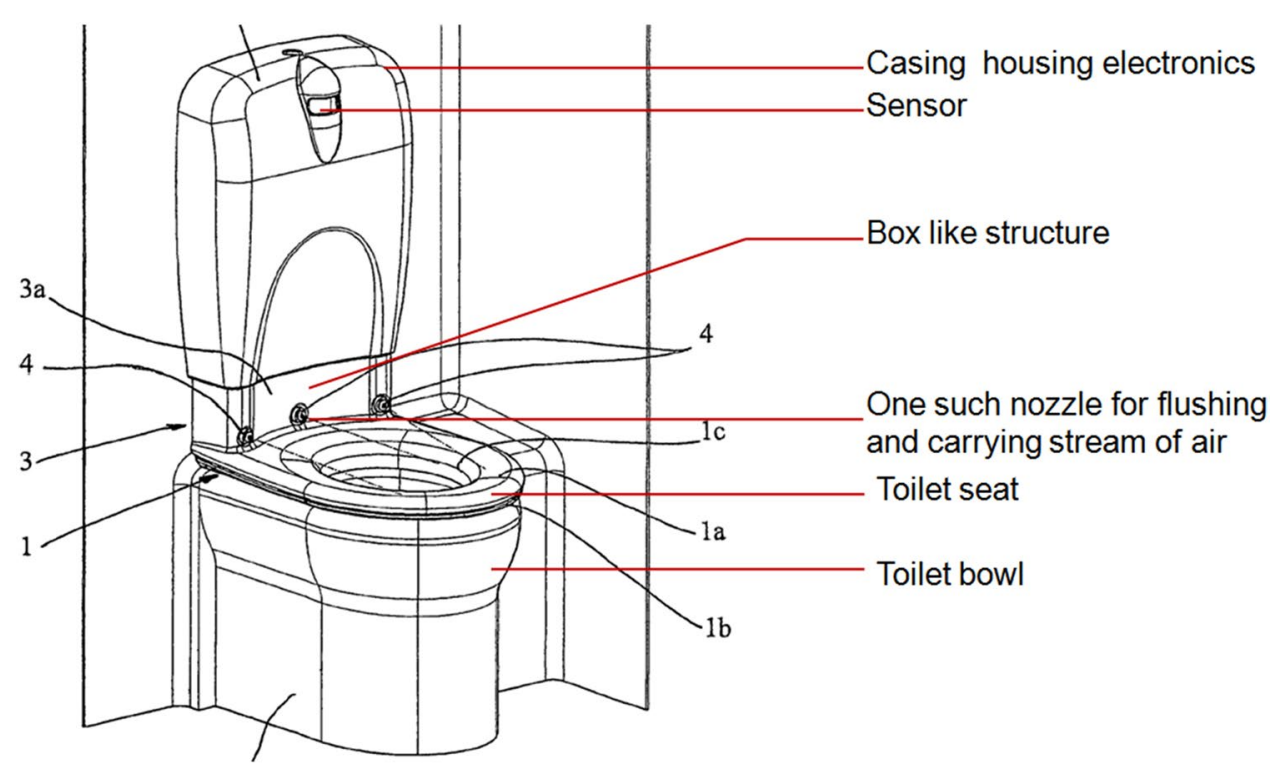


are activated. As a result, first the upper surface of the seat is flushed with sanitized water through the nozzles and then it is provided with hot air to dry the surface. The toilet seat has a design with the outer edge of the seat having a passage. The waste water after washing the upper surface of the seat will flow into this passage without splashing the water on to the floor. This water will be drained into the bowl through a channel that connects the outer edge and inner edge of the toilet seat. A similar device was proposed by Dorra which consist of a seat cover housing at least one outlet each to dispense water and gas, a motor pump to induce flow of water from water source to the water outlet and an air blower (Dorra 2016). The water and gas outlets are positioned at the back end of the toilet seat. The seat cover is designed in such a way that, when closed, water is discharged through the outlet and the air blown by the blower allows the flow of this water from back end to the front end of the toilet seat. This ensures the cleaning of the entire upper surface of the seat. The seat also include a plurality of Ultraviolet (UV) light source which may emit UV light after rinsing and blowing air to anti-microbialy disinfect the toilet seat. To install the devices put forward by Ermini and Dorra, infrastructural modification is required in the existing toilets and these devices are meant to be installed onto a single toilet commode.

Graves et al. (2009) had proposed a design of a toilet cleaning apparatus, as illustrated in Fig. 5a, that can clean the toilet seat without spraying water and air drying. The inventors claim that the design of the device is less complex, it is less expensive and the apparatus can be fixed on to an existing toilet commode without any infrastructure modifications. The device, a seat, is hinged to fit on a toilet commode between the existing toilet lid and rim of the toilet. There are two pedal controls, of which, one is used for lowering and lifting the seat via a pivot drive employing a motor. As shown in Fig. 5b, c, the seat is oval in shape having a top

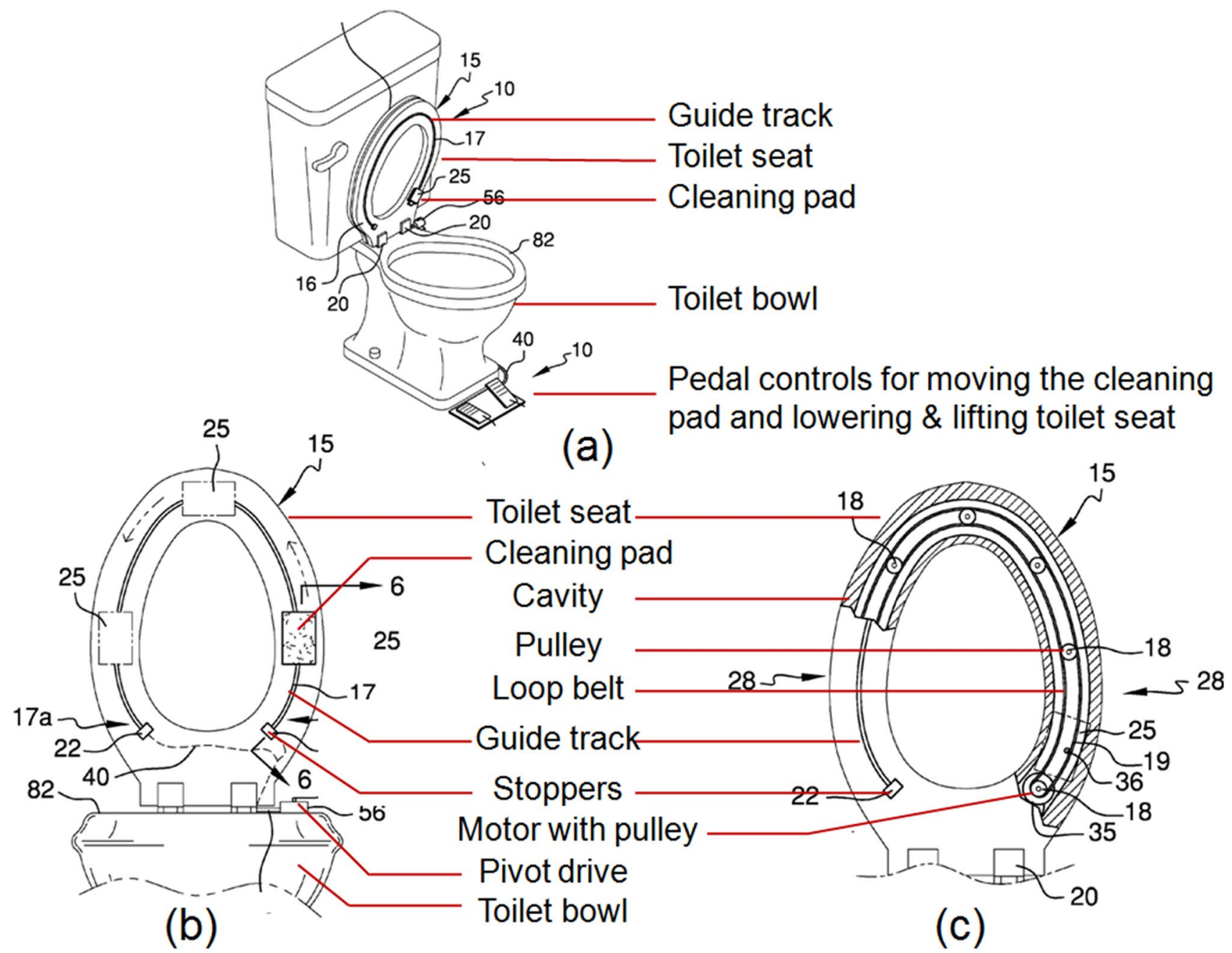

Fig. 5 a Design of toilet cleaning apparatus proposed by Graves et al.; b bottom view of the toilet seat while the seat is lifted; $\mathbf{c}$ partial cross sectional view of bottom part of toilet seat while seat is lifted (Graves and Graves 2009) 
portion, a bottom portion and a cavity in between. Within the cavity, there is an arrangement employing a motor with a pulley and several pulleys placed spaced apart which are connected via a continuous loop belt. In the bottom portion of the seat, there is a guide track and both the ends of the guide track have stoppers which can be tactile switch sensors. A drive attachment is affixed on to and propelled by the belt which will be guided by the previously mentioned guide track. Now when the motor is powered on, the belt is propelled and the drive attachment moves between the stoppers at the two ends. A cleaning pad with various cleansing agents is attached below the drive attachment and as it moves, the pad cleans the upper surface of the rim. Once the drive attachment reaches one end, this will be sensed by the stopper and ceases the motor power. To move it again in reverse direction, the pedal control designated for turning on the motor to move the cleaning pad should be pressed again. The major advantage of the design is that, no infrastructure modification is required in the toilet to install the device.

Most of the designs discussed above, other than the toilet cleaning brushes, pertain to toilet seat cleaning systems and these devices are not meant for cleaning $\&$ sanitizing the inner surface of a toilet commode. Unlike these devices, Nunez et al. had patented a design of a toilet bowl selfcleaner, that can be used to clean the inner surface of the toilet commode (Nunez and Chavez 2009). The device as shown in Fig. 6 is attached on to the rim of the toilet commode. It consists of a container to hold cleaning solution, a dispenser to spray cleaning solution, an electric motor and associated mechanisms to move the device throughout the length of the toilet rim and a motorized foldable brush. When the toilet seat is at a lowered position, the device is turned off. Once when the seat is lifted, the tactile sensor within the device senses this motion and energizes the motor. This moves the device along the length of the rim at a predetermined speed. Simultaneously, the dispenser will

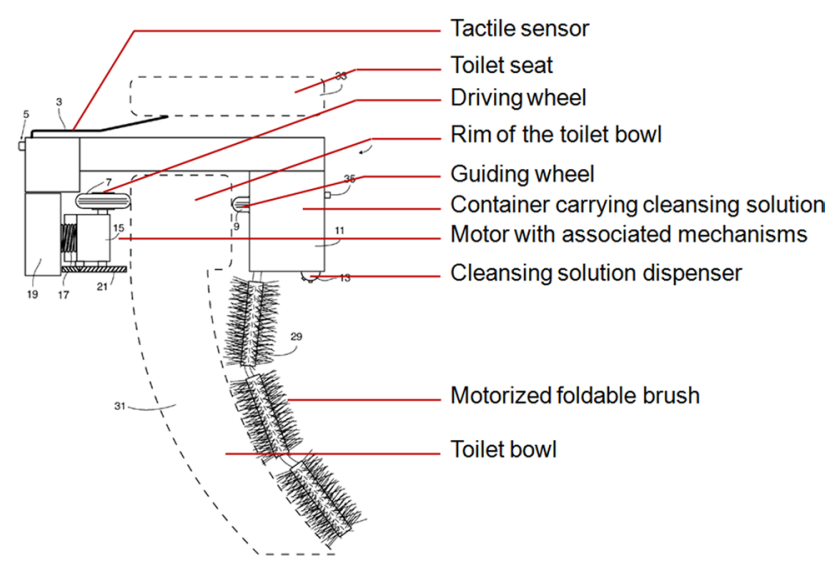

Fig. 6 Design of toilet bowl self cleaner proposed by Nunez et al. (2009) spray the cleaning solution and another motor will rotate the brushing arm that will perform the cleaning and sanitation of the inner area of the toilet bowl. Another sensor is also provided to sense the stopping point, so as to stop the device travelling further along the length of the rim by shutting off the motor. The device can be fixed on to a single toilet commode to serve that commode alone or a single device can be used to clean multiple toilet commodes in a public toilet.

Figure 7 a depicts a design of a toilet bowl cleaning assembly, attached to a toilet bowl, proposed by Ba-Akeel and Ghaemi (2011). As shown in Fig. 7b, the device has an elongated housing with an inverted L-shaped telescopic height adjustable member on top acting as a handle. A rotatable cleaning brush mechanism is downwardly attached to the bottom portion of the housing. The brush mechanism is equipped with a spring actuated-telescopic central shaft having a cleaning head at its bottom and it is aligned in the same axis as that of the housing. The cleaning head has several bristles in it which extends downwards from the central shaft. The brush mechanism is also equipped with a pair of lateral shafts extending downwards from the central shaft with an angle as shown in Fig. 7b. Each of the lateral shafts is spring actuated and telescopic, having a bend on its distal end with several bristles attached to it. A drive mechanism is mounted inside the housing which includes a motor that will rotate the central and lateral shafts when the switch provided in the handle is operated to achieve cleaning of the inner surface of the bowl. The power required for the functioning of the drive mechanism is drawn from a battery which is also included in the housing. The toilet bowl cleaning assembly is designed to have a cover coupled to the housing between the handle and the brush mechanism to avoid splashing of water towards outside while cleaning. The bottom portion of this cover can be attached to the upper edge of the toilet bowl using the clips provided. The cover consists of several panels hinged on to the housing and are expandable outwards from the housing to increase the diameter at the bottom part of the cover. The housing also has a fluid chamber which is coupled to the brush mechanism and it can provide cleansing fluid to the brush mechanism while cleaning. The fluid can be filled using the inlet provided near the housing and it will be ejected out through the outlet nozzles provided in the central and lateral shafts due to centrifugal force caused by the rotation of the shafts. No infrastructure modification is required to use this device and it can be used to clean multiple toilet commodes in a toilet complex without the need of installing it on to each toilet commodes.

Qualls et al. conceived a method to automatically clean a toilet bowl and the same is illustrated in Fig. 8a, b (Qualls and Jones 2017). As shown in Fig. 8b, their design was quite complicated and had two circular tracks spanning the entire circumference of the upper - outer surface of a circular shaped toilet rim, below the seat cover. Out of the two tracks, 


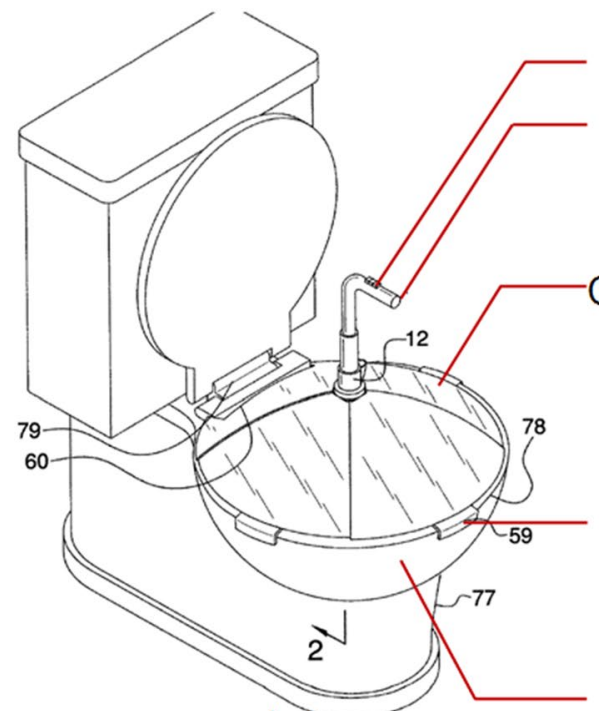

(a)

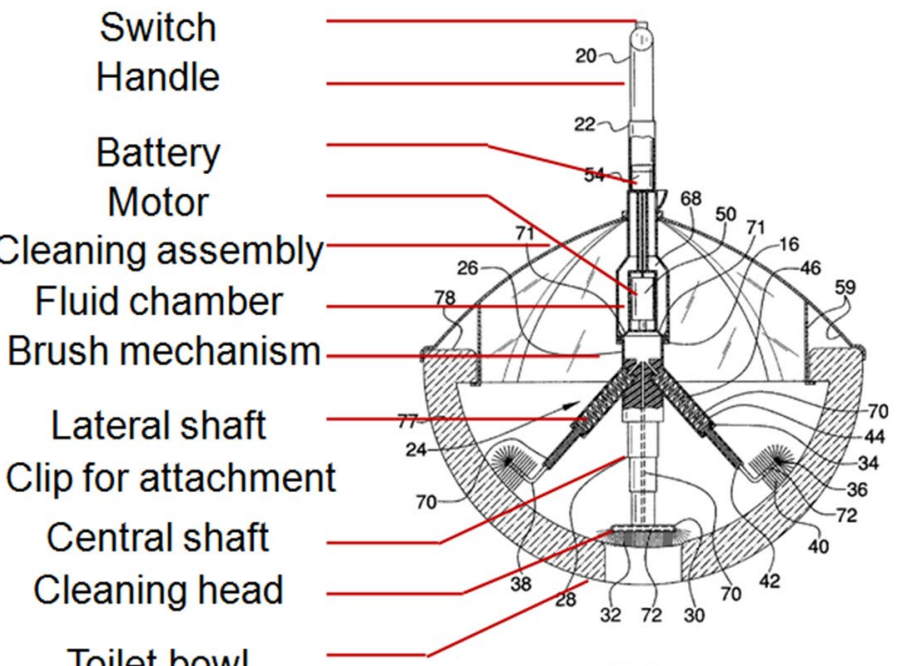

(b)

Fig. 7 a Toilet bowl cleaning assembly designed by Ba-Akeel et al. attached onto a toilet bowl; b Cross-sectional view of the toilet bowl cleaning assembly (Ba-Akeel and Ghaemi 2011)

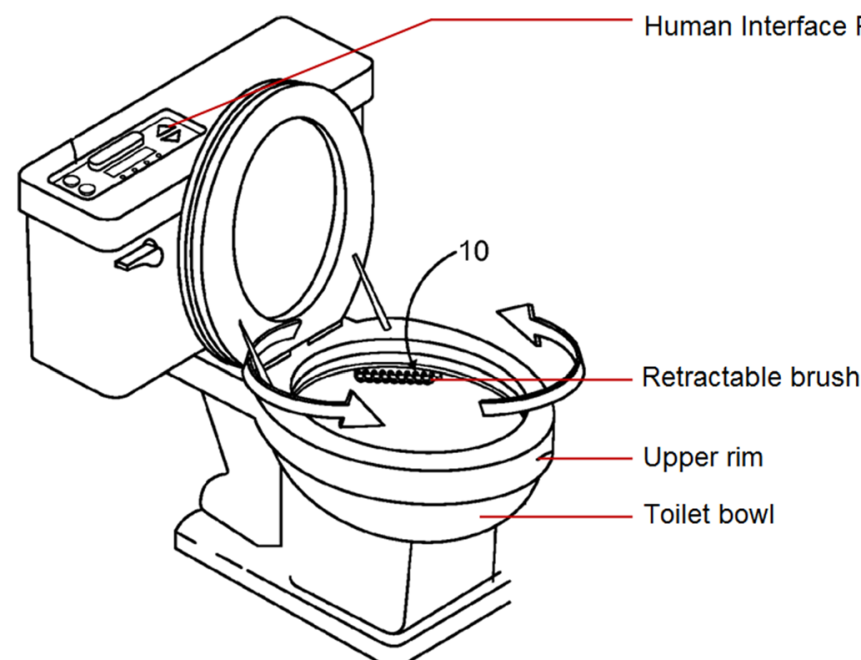

(a)

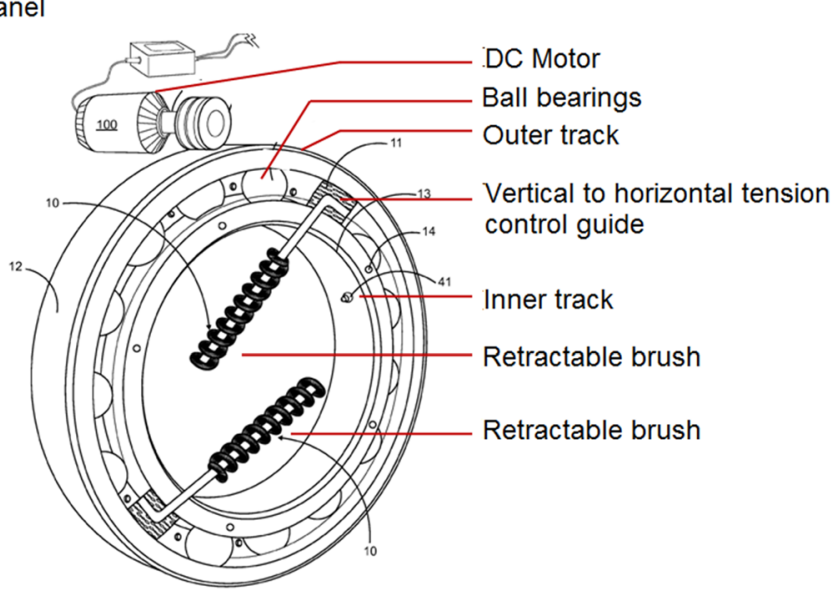

(b)

Fig. 8 a Design of the device proposed by Qualls et al. to automatically clean a toilet bowl; $\mathbf{b}$ A cross-sectional perspective top view under the rim (Qualls and Jones 2017)

the inner track is rigidly fixed or bolted to the inner part of the rim. The tracks are coupled with each other using motion transfer balls such as in ball bearings and thus, arresting the motion of the inner track will allow the outer track to spin freely. A pair or more of retractable brushes (spiral in shape) are movably fixed to a vertical to horizontal tension control guide which is adapted to move along the outer track as it spins. With the help of a DC motor, making use of suitable motion transfer mechanisms, the outer track is made to spin. When the track spins in the clockwise direction, the vertical to horizontal tension control guide forces the brushes to engage with and clean the vertical inner walls of the toilet bowl. In reverse direction, the brushes are forced to retract horizontally to the upper rim of the toilet bowl. The cleansing solution is dispensed into the bowl through the existing water pathway between the commode and the flush tank. An infrared sensor is positioned inside the bowl to detect debris obstructing the water line. Flushing and opening or closing of the toilet cover are also automated. The entire device is microprocessor controlled and the complete cleaning of 
the bowl is achieved through seven timed cycles-close lid cycle, automatic flushing cycle to flush the bowl with water, sensing cycle to check for debris, chemical release cycle to dispense cleansing solution, a cleaning cycle where the brushes spin vertically in clockwise direction, a cleaning cycle where the brushes retract and spin horizontally in counter clockwise direction and open lid cycle. The entire cleaning process can be controlled by the user using the human interface panel provided on the flush tank. The major disadvantage of this system is that, it has a complex design and moreover, it can only be employed in toilet commodes with circular shaped rim.
Recently, a design of an antimicrobial self-cleaning toilet was proposed by Hall et al., which is shown in Fig. 9 (Hall et al. 2018). The invention consists of a steep interior-titanium dioxide coated toilet bowel, a rinsing toilet seat with lid, a water tank and a helical loop trapway. The rinsing seat with the lid is hinged on to the upper portion of the toilet bowl in a manner similar to the attachment of conventional toilet seat and lid to the toilet commode, but using electrical motors. The seat is designed to have a cavity, along its inner circumference, with an array of nozzles to facilitate dispensing of water on to the vertical wall of the toilet bowl in an oscillatory and overlapping pattern with enough pressure.

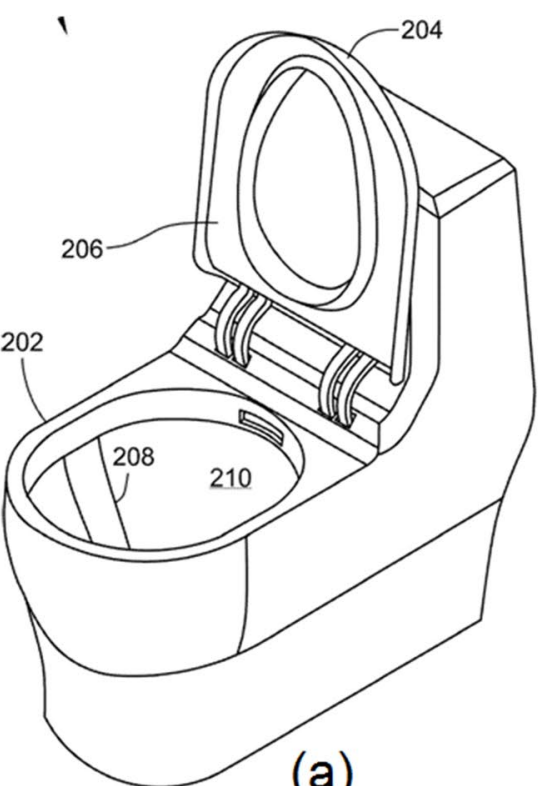

(a)

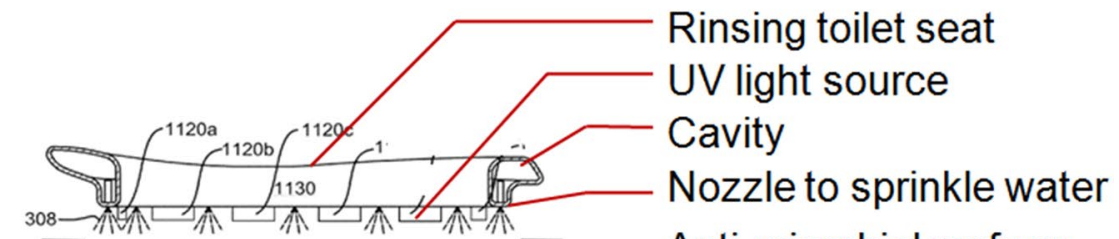
Anti-microbial surface

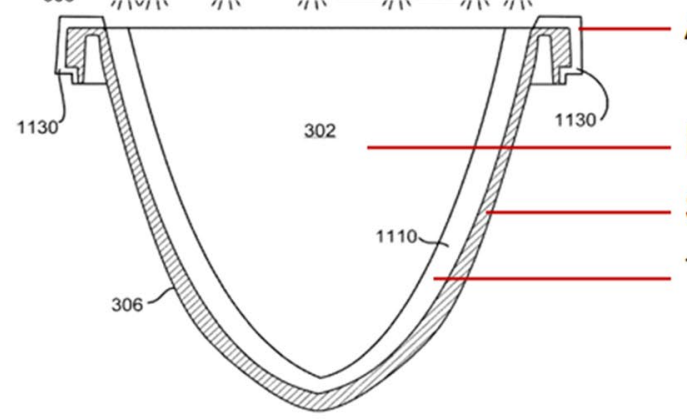

Rimless toilet bowl Steep interior wall Titanium dioxide coating

(b)

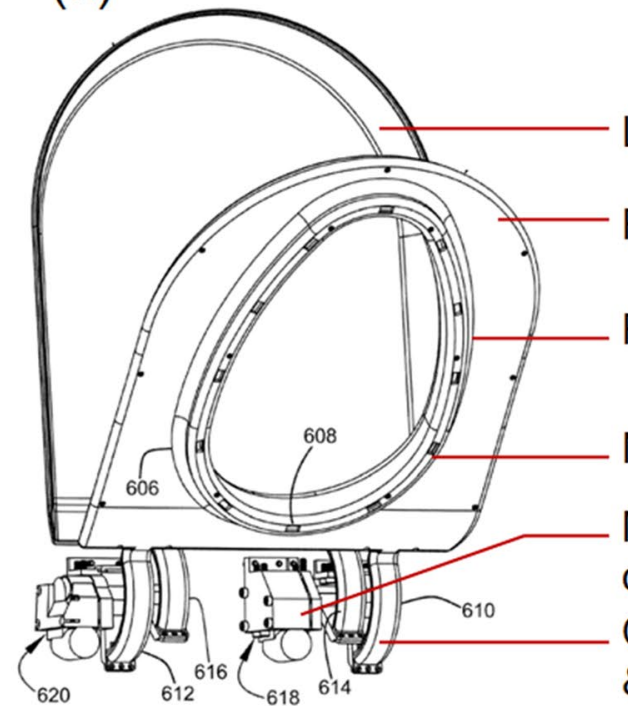

Lid

Rinsing toilet seat

Ring shaped ridge

Nozzle to sprinkle water

Motor and other mechanisms to open and close the seat \& lid

Cavity to carry water tubes

$\&$ wires

(c)

Fig. 9 a Design of an antimicrobial self-cleaning toilet proposed by Hall et al. b Rinsing seat with nozzles and UV source placed above rimless bowl and c Lid and rinsing seat arrangement (Hall et al. 2018) 
This ensures that the entire inner surface of the bowl is cleaned efficiently. The water for rinsing comes from a remote water source which can be controlled independently from the flush water tank. The flush water tank incorporated in the design also facilitates in storing water and once dispensed, the water will be flushed through the helical loop trapway. A range of sensors is employed in the device and with the help of a microprocessor the device operates automatically. For example, the sensors detect whether the user is sitting on the toilet seat and once the user finishes toileting, the action will be detected and subsequently the toilet lid will be closed automatically to flush. If the user intends to urinate by standing in front of the commode, the associated sensors will detect the user and the processor in turn will open the lid to facilitate the same. Sensors are also incorporated in the toilet seat to measure the weight of the user and determine the volume of water to be dispensed through the dispensing seat. The bowl is coated with titanium dioxide and also includes an array of UV light source on the upper circumference of the rimless bowl. This light source is capable of emitting UV rays of about $520 \mathrm{~nm}$. After flushing, the ultraviolet light sources will be turned ON automatically to activate the antimicrobial properties of titanium dioxide.

\subsection{Commercial toilet cleaning devices}

Even though several designs of lavatory cleaning devices have been proposed in patent documents, there exist only three predominant market players in this segment.

\subsubsection{SpinX-Toilet cleaning robot}

SpinX is a fully autonomous toilet cleaning robot developed by SpinX Robotics, Inc., Israel (SpinX World's 2019). The robot, shown in Fig. 10, is designed to clean the toilet seat and bowl in $90 \mathrm{~s}$. The robot consists of a robotic arm with a spinning cleaning brush as end-effector, that can reach every nook and corner of the internal wall of the toilet bowl and an array of water jets for rinsing the toilet seat followed by hot air blowers for drying the same. These mechanisms are incorporated inside a specially designed toilet lid and can be fixed on to a conventional standard western toilet commode by removing the existing toilet lid. The robot can be either battery operated or plugged on to the power socket. To initiate cleaning, the lid should be gently pushed downwards resulting in smooth and gentle closing of the lid and subsequently a button is pressed. The robot makes use of a dynamic toilet bowl scanning system employing a smart sensor/array of sensors that can scan the inner surface of the toilet bowl. This enables the robotic arm to reach and scrub the inner walls of the bowl, irrespective of size, shape or model of toilet commode used. Once after scanning, the robotic arm hidden inside the lid cover expands downwards

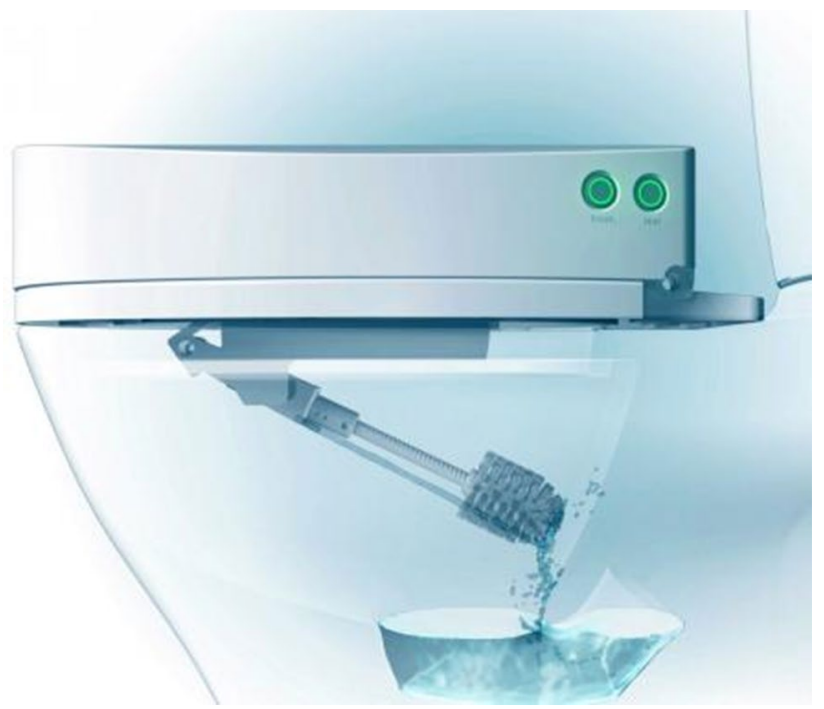

Fig. 10 SpinX toilet cleaning robot attached to a toilet bowl; Image Courtesy: SpinX Robotics, Inc

with a spinning brush to clean the inner wall. Water mixed with detergents or disinfectants will be dispensed as a jet stream from the distal end of the robotic arm towards the inner wall for both cleaning the wall and for self-cleaning of the spinning brush. After cleaning the wall and self-cleaning of the brush, the robotic arm will be tucked itself inside the lid. Meanwhile, the toilet seat is also rinsed by dispensing water jets through an array of nozzles provided underneath the lid and later the seat is dried by blowing compressed air. The company claims that, the robot is compactable to fit in $98 \%$ of western toilet commodes available in market and it's rechargeable lithium-ion battery can serve up to 50 cleaning cycles (Chang 2017; Mlot 2017).

\subsubsection{Giddel toilet cleaning robot}

Giddel is a patent pending (D'Souza et al. 2019), portable toilet cleaning robot developed by Altan Robotech Inc., USA (Robotech 2019). It can be suspended over the toilet using the mounting bracket provided, so that it's body does not come in contact with the bowl or the water. This battery operated codeless robot has a rotary body with a telescopic robotic arm with a brush at its end that can reach and clean toilet bowl of a variety of sizes $\&$ shapes. The robot is designed to have a triple joint configuration of two rotary and one linear joints and this results in its dexterity to scrub top, under and inside portions of the rim along with the entire vertical wall of the bowl down to the drain. The cleaning is performed in three different motions-circular or radial motion, sinusoidal or wavy pattern and vertical motion towards the drain. Giddel's software is designed in such a way that, with the help of tactile feedback, the 
bowl's curvature is measured and the arm is provided with 3D coordinates for reaching all surfaces that need cleaning. The robot has a heavy duty anti-microbial, electrically safe plastic housing which can even withstand acidic environment in the toilet. Provisions of inbuilt reservoir and pump are also incorporated in the robot to rinse the bowl with water mixed with disinfectants (Arar 2018; Wetzel 2019). Figure 11 shows Giddel robot being attached to a toilet bowl.

\subsubsection{Toibot}

An Israeli start up has come up with a battery operated toilet cleaning robot christened Toibot (2019). The small sized robot that follows a toothed plastic track positioned around the rim, below the toilet seat. It has a uniquely designed, elastic, replaceable brush that can reach any point in the toilet bowl. The robot moves in 3 axes i.e. moving around the toilet rim following the track and up and down motion of the brush connected to a motorized arm mechanism which may resemble a motion similar to the steel tape extending and retracting from a retractable measuring tape. In addition to this, the brush also spins about its own axis to achieve effective and efficient cleaning. The robot also comes with disinfectant tablets which can be inserted into the device in the slot provided. Once the robot is switched on, the robot will clean the inner wall of the toilet bowl following the above mentioned motions and ceases its operation automatically once one rotation is made around the rim successfully.

\section{Challenges and issues}

The devices mentioned in Sect. 2 are evaluated based on three major aspects- functionality and efficiency, affordability and water resources that they require to perform cleaning. As mentioned in the introduction section, cleaning public lavatories with a brush or brush like equipment

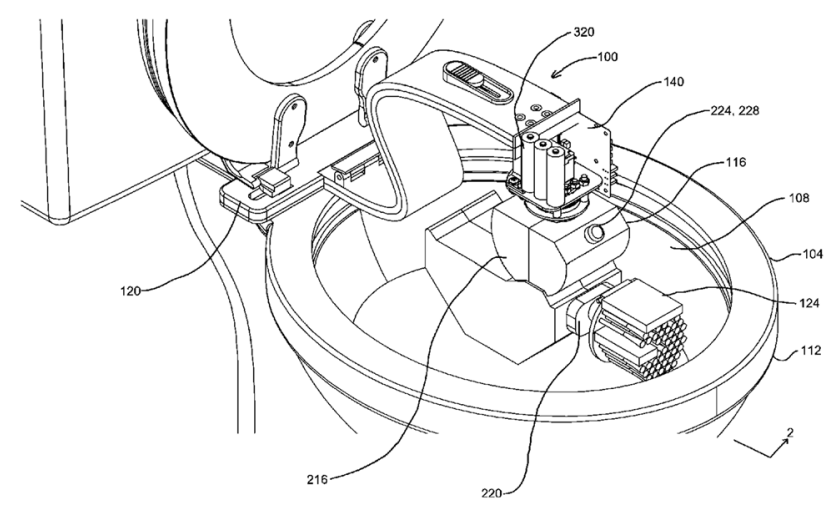

Fig. 11 Giddel robot attached to toilet commode (D'Souza et al. 2019) is a humongous task which involves a lot of time and effort. Using electrically powered brushes may reduce the physical effort of scrubbing the bowl, but the time involved in cleaning will be the same as that of conventional cleaning. Also, it will be difficult to ensure that every corner of the bowl is cleaned while using such equipment. While the designs put forward by Yu, Sadegh et al., Pellati, Blatz et al., Ermini, Dorra and Gravis et al. are meant for merely cleaning the toilet seat, designs of Nunez et al., Ba-Akeel et al., Quallas et al. and Hall et al. are meant only for cleaning the toilet bowl. In commercial devices, Giddel toilet cleaning robot and Toibot are also employed for cleaning the inner part of the bowl and not the toilet seat. An efficient toilet cleaning device should effectively clean both the toilet seat and the inner wall of the bowl. SpinX toilet cleaning robot satisfies this requirement, as it effectively cleans the bowl as well as the toilet seat. Still, it has its own disadvantages when it is being used in public toilets having several lavatories to be cleaned, especially in developing countries.

The SpinX toilet cleaning robot is not yet commercially released in the market and the retail price of the device is expected to be around $\$ 350$ (Marquis 2017) which would be unaffordable, as this robot is meant to be fixed to a single toilet commode. As public toilets house several numbers of toilet commodes, equal number of SpinX robots are needed to be installed which would be a financial burden for the operators, both government and private, in a developing country like India. The case is same with the designs proposed by $\mathrm{Yu}$, Sadegh et al., Pellati, Blatz et al., Ermini, Dorra, Graves et al., Qualls et al. and Halls et al. Giddel Toilet cleaning robot costs around \$399.99 (Giddel Toilet Cleaning Robot Kit 2019), but the advantage is that a single robot can be employed to clean multiple toilet commodes. Toibot is also not commercially released into the market and it may cost between $\$ 99$ and $\$ 149$ (Toibot 2019) which is comparatively more economical than SpinX and Giddel. Toibot also has the disadvantage that the service of one unit of robot is restricted to a single toilet commode. Moreover, most of the toilet seat cleaning devices, bowel cleaning devices and the commercial devices discussed in this paper have a complicated design and remove the intervention of humans completely, while cleaning. Hence, a low-cost semi-automated lavatory cleaning device may serve as a solution against the costly fully autonomous system. Table 1 provides a comparison of toilet cleaning devices discussed in Sects. 2.1 and 2.2.

The devices discussed in Sect. 2 wash the toilet seat/bowl with water. None of the research works reported in literature clearly specifies the quantity of water needed by the devices to clean. Shortage of water resources is a serious issue around the world and researchers recommend reuse of treated sewage water as a solution to this (Ren et al. 2019). Even though, this treated water can be used for toilet cleaning purposes, toilet cleaning devices should be designed to 


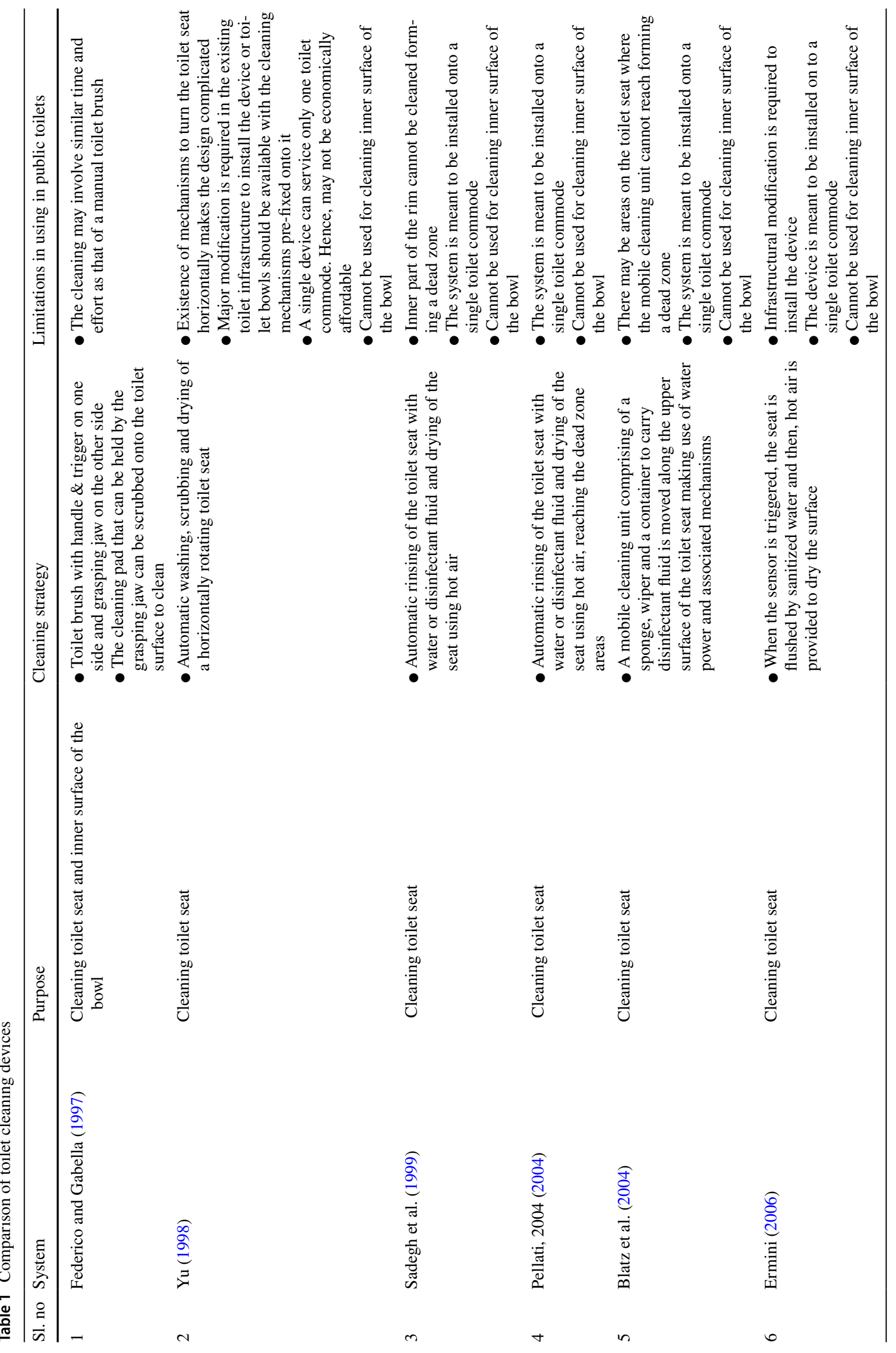



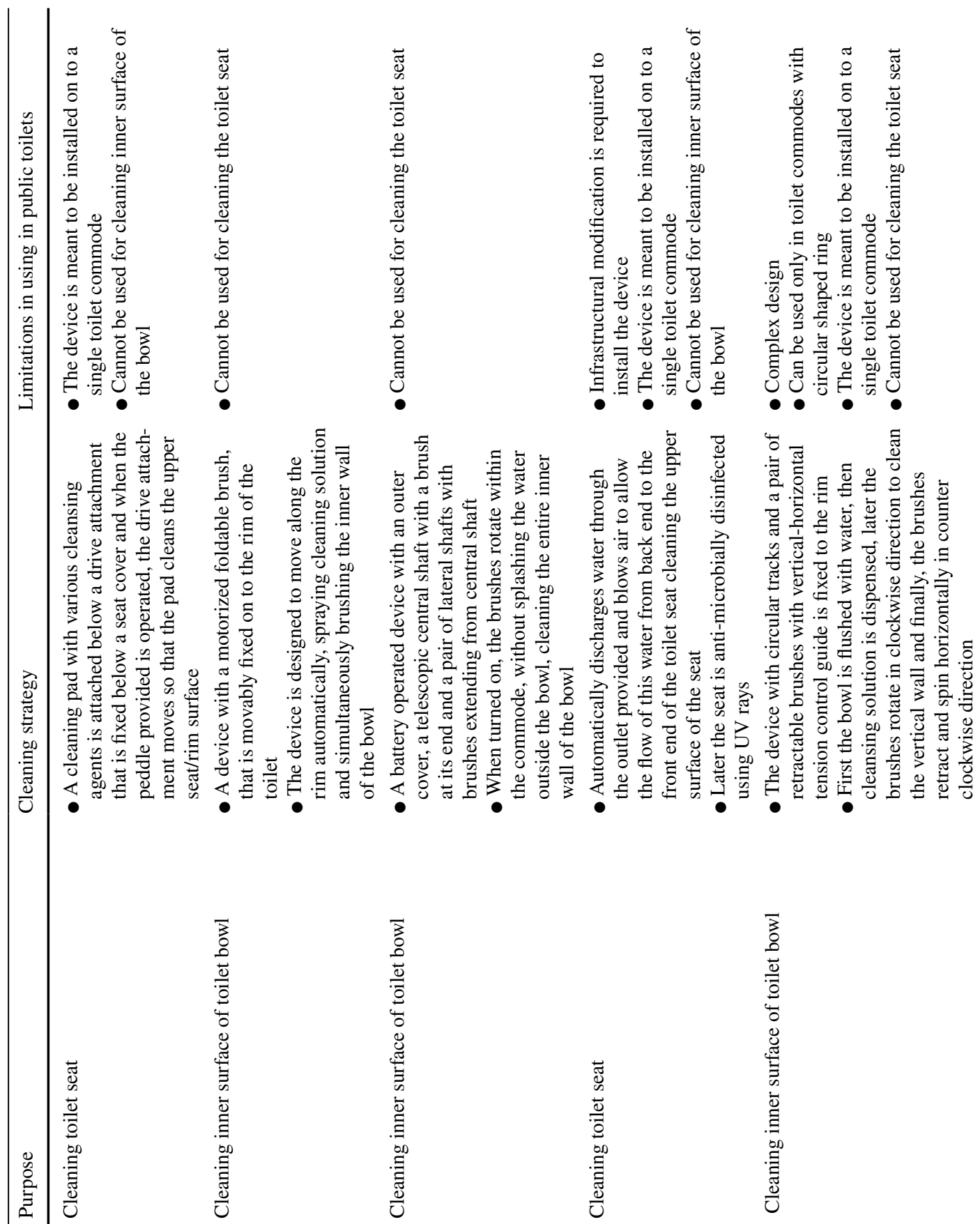

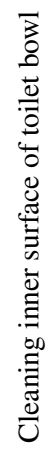

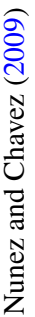

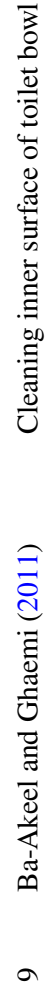

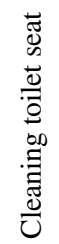

ㅇ
0
0
0
0
0
0
0
0
0
0
0
0

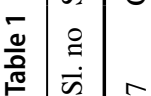

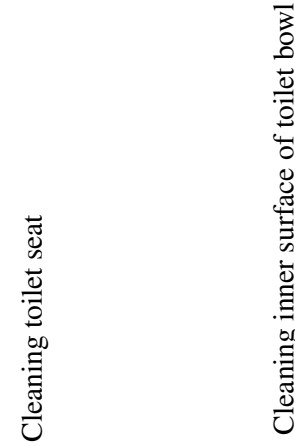

6
0
0
0
0 


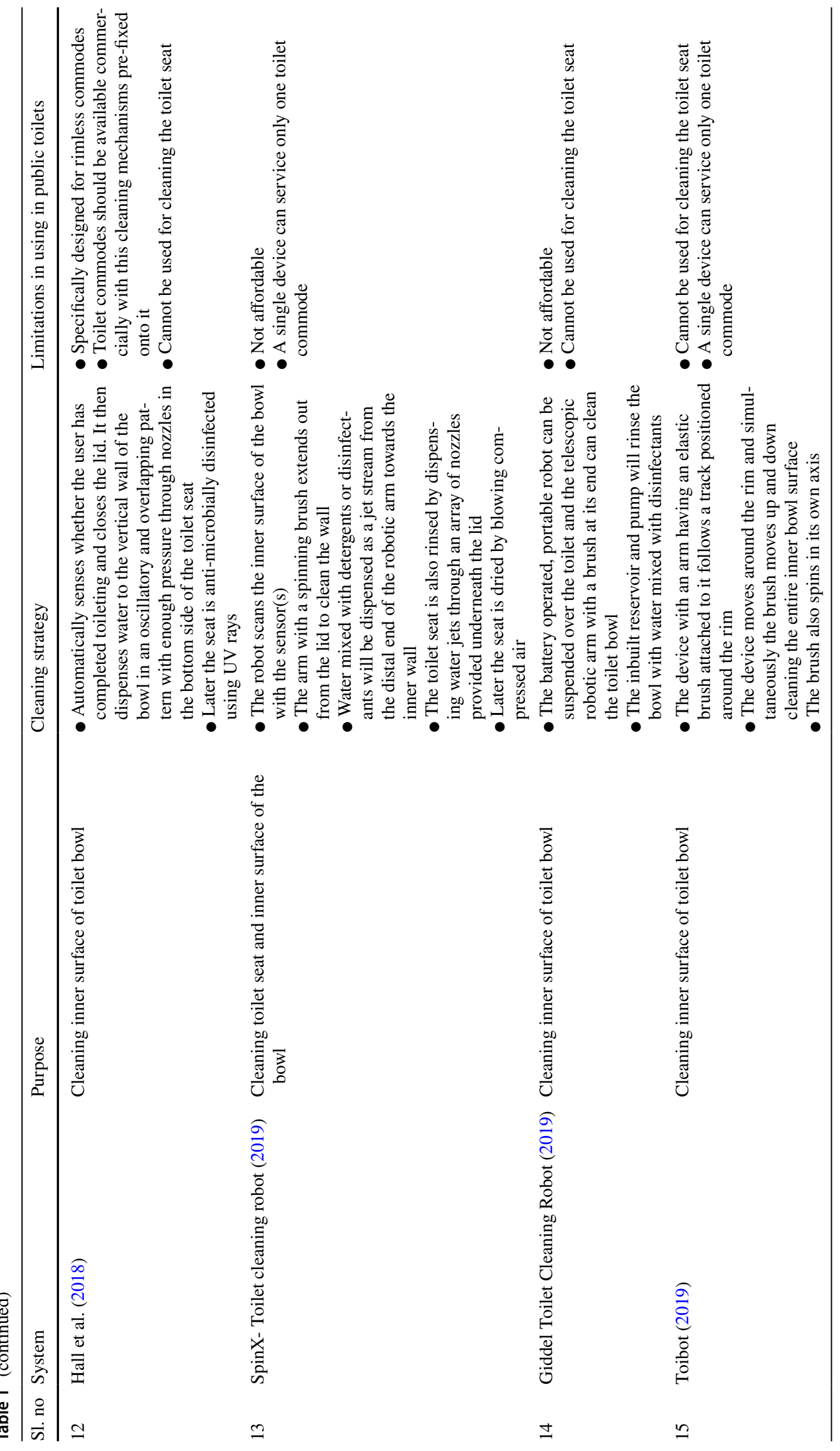


use less water for cleaning. Another important issue that needs to be considered while designing such a device is to ensure that all electronics sub-systems are enclosed properly in waterproof chambers to avoid damage due to contact with water or moisture (Krishnan and Pugazhenthi 2014). Consideration of the weight of the toilet cleaning device may have been rendered irrelevant for devices mentioned in literature because these are to be fixed on to the toilet commode and aimed to be employed in domestic toilets. However, this parameter becomes an important design consideration for devices intended to be used in public toilets.

Squatting toilet commodes are used widely in most of the Asian and African countries (Krishnan 2019). None of the devices discussed in Sect. 2, except the brush like equipment can be employed to clean squatting type toilet commodes. Hence, developing a single device that shall clean and sanitize both western and squat type toilet commodes can be thought off. With such a device, public toilets housing both western and squat type commode can be cleaned without the need for separate devices for the two types. The semiautomated device shall ease the cleaning process keeping purchasing cost to a minimum and such a device shall curtail the role of man power only to a small extent so that it does not result in unemployment leading to a win-win situation.

\section{Design considerations of a semi-automated lavatory cleaning device}

Maneuverability is an important factor for the semi-automated lavatory cleaning device under consideration, as it is meant to be used in places where there are several numbers of lavatories. The design should be in such a way that, the user can easily push or pull the device to maneuver it above a toilet commode. The device should be accommodated inside a toilet cubicle of minimum size $0.9 \mathrm{~m}(\mathrm{~L}) \times 0.75 \mathrm{~m}(\mathrm{~W})$ (MoHUA 2018) housing a sitting type western toilet bowl with dimensions $\sim 0.393 \mathrm{~m}(\mathrm{H}) \times 0.425(\mathrm{~L}) \times 0.365(\mathrm{~W})$ or a squat commode with dimensions $\sim 0.585 \mathrm{~m}(\mathrm{~L}) \times 0.460 \mathrm{~m}$ (W) with a depth of $0.250 \mathrm{~m}$. Also, as mentioned in Sect. 3, the weight of the device is an important design criterion. The user should be able to push or pull the device to manoeuvre it within the restroom and at the same time, the device should be sturdy enough as it should not vibrate much or move during the cleaning process.

The device is expected to clean the toilet seat, rim, inner edge of the rim and the inner vertical wall of a western toilet bowl as well as the foot placement area, inner edge of the rim $\&$ inner bowl surface of a squat type commode. It shall have brushes with proper mechanisms for scrubbing the surfaces of the toilet commode and shall also have nozzles to sprinkle water mixed with cleansing agents, in order to rinse the cleaning surfaces. Provisions to blow hot air so as to dry the cleaned surfaces can also be incorporated in the device under consideration. As mentioned in Sect. 1, aerosolization of the germs while cleaning or flushing may lead to respiratory diseases and hence the device shall be designed to clean the toilet bowl in an enclosure preventing the aerosolized germs from spreading into the toilet environment. Provisions to scan the inner surface of the toilet bowl can also be incorporated, as in SpinX toilet cleaning robot, but with low-cost sensors so that the brush mechanism can reach every corner of the bowl irrespective of its size and shape.

As the device is expected to be employed in a public toilet with several numbers of lavatories and as these lavatories have to be cleaned frequently, the power for its functioning can be drawn from the power socket via wires with proper insulation to avoid possible electric shock due to water or moisture contact. A Switch Mode Power Supply (SMPS) can be employed in the device to convert the alternative current (AC) to required direct current (DC). Using battery power source may not be feasible as the batteries need to be charged frequently. The device shall also have a simple user interface that shall help the user to operate the device with ease.

In addition to this, an Internet of Things (IoT) based sanitation monitoring and compliance system can be embedded into the proposed toilet cleaning device to ensure timely cleanliness of the lavatories in public toilets. The sanitation monitoring and compliance system may include Radio Frequency Identification (RFID) tags having unique identification codes attached to each toilet commode. The lavatory cleaning device may employ an RFID reader which will align with the RFID tag of the commode when the device is manually aligned over the commode before starting the cleaning process. The reader scans the RFID tag and updates a cloud database with information such as public toilet ID, lavatory ID, time of cleaning, cleaning duration, whether the cleaning was successfully completed and so on. The information updated in the database will help the concerned authorities to monitor and ensure timely cleanliness of public toilets and cleaning activities of the sanitary workers.

Employing a camera and a deep learning algorithm, implementation of a commode cleanliness classification system can be thought off to classify the cleanliness levels into three categories- 'dirty', 'satisfactory' and 'clean'. After the device is aligned on to the commode, the camera captures the image of the inner wall and the deep learning algorithm will suggest the cleanliness level to the device. The device, based on the suggested level will automatically choose and perform a cleaning sequence in order to clean the commode. For example, if the suggested level is 'dirty', the cleaning sequence will involve rinsing the wall with more water and rigorous scrubbing using the brush. On the other hand, if the suggested level is 'clean', the cleaning sequence 
will use less water and normal scrubbing of the inner wall. Once the cleaning sequence is completed, the camera will again capture the image of the inner wall and the learning algorithm will again classify the cleanliness level for confirmation of cleanliness. If again the level is not as desired, the cleaning sequence will continue. By implementing this smart cleanliness classification system, both cleanliness of the lavatory and optimal use of water \& other resources can be ensured. Finally, after incorporating the above mentioned functionalities and features in the design, the device shall cost below \$200 when commercialized, making it affordable for the developing world.

\section{Conclusion}

Cleaning toilet commode is an unpleasant task and cleaning public toilets housing several such commodes make the task back-breaking. This article presents a brief review on various lavatory cleaning devices, focussing on designs available as patent documents and commercially available toilet cleaning robots. The devices discussed in the article and the commercial toilet cleaning robots- Giddel and Toibot, either clean only the toilet seat or wash only the toilet bowl. SpinX is the only robot that satisfies both the requirements but it is not affordable to be used in public toilets in developing countries, as each of the toilet commode in a public toilet may require individual robot fixed on to it. A manually manoeuvrable device that can clean multiple toilet commodes of both sitting and squatting type and that satisfies the discussed design criteria is the need of the hour. This cost effective, semi-automated toilet cleaning robot may serve as a fast and easy solution to effectively clean public toilets in developing countries without completely removing human intervention.

Funding Not applicable.

\section{Compliance with ethical standards}

Conflict of interest The author has no potential conflict of interests.

Availability of data and material Not applicable.

Code availability Not applicable.

\section{References}

ASEAN: ASEAN Public Toilet Standard. Jakarta, Indonesia (2016). Ahmed, O.B.: Evaluation of the antimicrobial efficacy of titanium dioxide nanoparticles on the surfaces of public toilets. Green Sustain Chem 8, 32-38 (2018). https://doi.org/10.4236/gsc.2018.81003
Arar, D.: Forget the fecal matter forever and let this toilet-scrubbing robot take over. In: Digit. Trends. https://www.digitaltrends. com/home/robot-toilet-cleaner/ (2018). Accessed 10 Aug 2019

Ba-Akeel, O.A., Ghaemi, S.: Toilet bowl cleaning assembly. US Patent 8,011,051B1 (2011).

Blatz, W., Lenhard, M., Heub-Schneider, A.: Device for cleaning a toilet seat. US Patent 20,040,040,075A1 (2004).

Chang, L.: Never clean a toilet again - SpinX robot does the dirty job. In: Digit. Trends. https://www.digitaltrends.com/home/ spinx-toilet-cleaning-robot/ (2017). Accessed 10 Aug 2019

Dolah, O.H.: Rotary brush cleaning device. US Patent 6,295,681B1 (2001).

Dorra, M.: Auto cleaning toilet seat and method of use. US Patent 9,339,158B2 (2016)

D’Souza, D., Bassalious, M., Mi, Z., Sarkar. P.K.: Robotic cleaning apparatus and related methods. US Patent 20,190,177,959A1 (2019).

Ermini, M.: Self-sanitizing toilet seat. US Patent 7,028,346B2 (2006).

Federico, V.L., Gabella, W.F.: Toilet cleaning device with cleaning pad. US Patent 5,630,243A (1997).

Gerhardts, A., Hammer, T.R., Balluff, C., et al.: A model of the transmission of micro-organisms in a public setting and its correlation to pathogen infection risks. J Appl Microbiol 112, 614-621 (2012). https://doi.org/10.1111/j.1365-2672.2012.05234.x

Giddel Toilet Cleaning Robot Kit. In: Alten Robot. https://altanrobot ech.com/product/giddel/. Accessed 10 Aug 2019

Graves, B.S., Graves, K.: Toilet cleaning apparatus. US Patent 7,509,693B1 (2009).

Greed, C.: The role of the public toilet: pathogen transmitter or health facilitator? Build Serv Eng Res Technol 27, 127-139 (2006). https ://doi.org/10.1191/0143624406bt151oa

Greenhalgh, R., Walker, J.T.: Antimicrobial strategies for polymeric hygienic surfaces in healthcare. Int Biodeterior Biodegrad 125, 214-227 (2017). https://doi.org/10.1016/j.ibiod.2017.09.009

Grover, A., Citro, B.: India: access to affordable drugs and the right to health. Lancet (London, England) 377, 976-977 (2011). https:// doi.org/10.1016/S0140-6736(10)62042-9

Hall, D.R., Butala, S.J.M., Reynolds, J., et al.: Antimicrobial SelfCleaning Toilet. US Patent 20,180,008,106A1 (2018).

Hamilton, K.A., Hamilton, M.T., Johnson, W., et al.: Health risks from exposure to Legionella in reclaimed water aerosols: Toilet flushing, spray irrigation, and cooling towers. Water Res 134, 261-279 (2018). https://doi.org/10.1016/j.watres.2017.12.022

Johnson, D.L., Mead, K.R., Lynch, R.A., Hirst, D.V.L.: Lifting the lid on toilet plume aerosol: a literature review with suggestions for future research. Am J Infect Control 41, 254-258 (2013). https:// doi.org/10.1016/j.ajic.2012.04.330

Krishnan, R.H.: A review on squat-assist devices to aid elderly with lower limb difficulties in toileting to tackle constipation. Proc Inst Mech Eng H 233, 464-475 (2019). https://doi.org/10.1177/09544 11919838644

Krishnan, R.H., Pugazhenthi, S.: Mobility assistive devices and selftransfer robotic systems for elderly, a review. Intell Serv Robot 7, 37-49 (2014). https://doi.org/10.1007/s11370-013-0142-6

Maiti, R., Bhatia, V., Hota, D., Padhy, B.: Essential medicines: an Indian perspective. Indian J Community Med 40, 223-232 (2015). https://doi.org/10.4103/0970-0218.164382

Marquis, M.J.: The SpinX Robotic Toilet Cleaner - Review. In: ireviews. https://www.ireviews.com/review/spinx-robotic-toile t-cleaner (2017). Accessed 2 Aug 2019

Mayberry, S.A.: Utility Brush. US Patent 4,353,144A (1982).

Mendes, M.F., Lynch, D.J.: A bacteriological survey of washrooms and toilets. J Hyg (Lond) 76, 183-190 (1976). https://doi. org/10.2307/3861735

Miller, A.J.: Power assisted toilet brush. US Patent 4,397,056A (1983). 
Mlot, S.: SpinX Toilet-Cleaning Robot Does Your Dirty Work. In: Geek,com. https://www.geek.com/tech/spinx-toilet-cleaning-robot -does-your-dirty-work-1722146/ (2017). Accessed 10 Aug 2019

MoHUA: Advisory on public and community toilets. New Delhi, India (2018).

Moss, A.B.S.: Toilet cleaning apparatus. US Patent 6,966,720B2 (2005).

Nunez, B., Chavez, I.: Toilet bowl self-cleaner. US Patent 20,090,044,322A1(2009).

Pellati, G.: Automatic device for washing a toilet seat ring. US Patent 6,772,451B2 (2004).

Qualls, P.D., Jones, A.R.: Method of automatically cleaning a toilet bowl. US Patent 9,644,358B2 (2017).

Querido, M.M., Aguiar, L., Neves, P., et al.: Self-disinfecting surfaces and infection control. Colloids Surf B Biointerfaces 178, 8-21 (2019). https://doi.org/10.1016/j.colsurfb.2019.02.009

Ren, X., Zhang, Y., Chen, H.: Graywater treatment technologies and reuse of reclaimed water for toilet flushing. Environ Sci Pollut Res 26, 1-11 (2019). https://doi.org/10.1007/s11356-019-05154-6

Robotech. https://altanrobotech.com/. Accessed 2 Aug 2019

Sadegh, A.M., Chaskel, M., Lebovits, G.I.: Apparatus for automatic washing, sanitizing and drying toilet seats. US Patent 6,003,159A (1999).

Sassi, H.P., Reynolds, K.A., Pepper, I.L., Gerba, C.P.: Evaluation of hospital-grade disinfectants on viral deposition on surfaces after toilet flushing. Am J Infect Control 46, 507-511 (2018). https:// doi.org/10.1016/j.ajic.2017.11.005

SpinX World's first toilet cleaning robot. https://www.spinxclean.com. Accessed 10 Aug 2019

Toibot.https://www.toibot.net/. Accessed 10 Aug 2019

Toibot FAQs. In: Toibot. https://www.toibot.net/f-a-q-s. Accessed 10 Aug 2019

WHO: Ten years in public health, 2007-2017: report by Dr Margaret Chan, Director-General, World Health Organization. World Health Organization, Geneva (2017).
Wetzel, K.: Hate poop? Then $\$ 500$ may not be too much to pay for this toilet-cleaning robot. In: Digit. Trends. https://www.digitaltre nds.com/home/giddel-toilet-cleaning-robot/ (2019). Accessed 10 Aug 2019

Yehuda, H.B., Lebenhartz, S.: Combination toilet cleaning device. US Patent 9,265,388B2 (2016).

Yu, Y.C.: Automatic toilet seat cleaning system. US Patent 5,806,105A (1998).

Publisher's Note Springer Nature remains neutral with regard to jurisdictional claims in published maps and institutional affiliations.

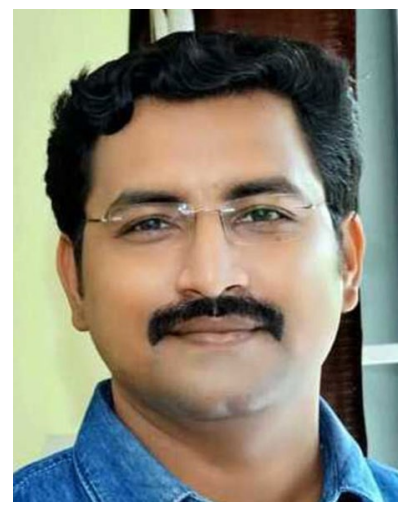

R. Hari Krishnan is serving as an Assistant Professor (Research) at SASTRA Deemed to be University, India. He received his M.Sc. in Electronics from Mahatma Gandhi University, India, and M. Tech. in Embedded Systems from Hindustan Institute of Technology and Science, India, in 2009 and 2010, respectively. He received his $\mathrm{Ph}$.D. from SASTRA Deemed to be University in 2017. His research interests include assistive \& rehabilitative robotics, service robotics, embedded systems and mechatronic systems. He is a member of IEEE, IEEE Robotics \& Automation Society and The Robotics Society of India (TRS). 